\title{
Título O Ciclo Intercultural de Iniciação Acadêmica em uma Universidade Estadual do Paraná: o fortalecimento dos indígenas na Educação Superior em uma experiência com a Educação Matemática
}

\author{
The Intercultural Cycle of Academic Initiation at a State University of Paraná: the \\ strengthening of indigenous people in Higher education in an experience with \\ Mathematics Education
}

\author{
Magna Natalia Marin Pires ${ }^{1}$ \\ Wagner Roberto do Amaral ${ }^{2}$ \\ Jean Carlos Alves da Silva Kuboyama ${ }^{3}$
}

\begin{abstract}
Resumo
Este artigo apresenta uma experiência de ingresso e permanência de jovens indígenas, habitantes no território paranaense, por meio do direito a vagas suplementares em Instituições Estaduais de Ensino Superior. Os inúmeros desafios de manter e formar os indígenas ingressantes, principalmente o de acompanhar as atividades acadêmicas, inspirou a criação do Ciclo Intercultural de Iniciação Acadêmica de Estudantes Indígenas, como uma estratégia de afirmação e fortalecimento da presença indígena na universidade. Após cursar o Ciclo Intercultural e obter o desempenho acadêmico previsto pela proposta pedagógica, o estudante indígena poderá se matricular no curso de graduação desejado. Neste artigo relatamos a importância da Matemática, uma das áreas de conhecimento abordadas por um educador-bolsista, e suas possibilidades em explorar as potencialidades e habilidades que o trabalho com Resolução de Problemas e as Investigações Matemáticas podem desenvolver nos profissionais de todas as áreas do conhecimento. O relato de parte de um episódio aula revela que a Matemática pode provocar a reflexão e oportunizar a participação ativa do estudante, tomando decisões, fazendo escolhas, testando a validade das suas escolhas.
\end{abstract}

Palavras-chave: "Educação matemática”, "Estudantes indígenas”, "Ciclo intercultural”, "Educação Superior Indígena".

\begin{abstract}
This article presents an experience of entrance and permanence of indigenous youth, inhabitants in the territory of Paraná, through the right to additional places in State Higher Education Institutions. The innumerable challenges of maintaining and training the native inhabitants, especially that of accompanying academic activities, inspired the creation of the Intercultural Cycle of Academic Initiation of Indigenous Students, as a strategy to affirm and strengthen the indigenous presence in the university. After attending the Intercultural
\end{abstract}

\footnotetext{
${ }^{1}$ Doutora em Ensino de Ciências e Educação Matemática pela Universidade Estadual de Londrina. Professor do Departamento de Matemática da Universidade Estadual de Londrina, Paraná, Brasil. Email: magna@uel.br.

2 Doutor em Educação pela Universidade Federal do Paraná. Professor do Departamento de Serviço Social da Universidade Estadual de Londrina, Paraná, Brasil. Email: wramaral2011 @ hotmail.com.

${ }^{3}$ Licenciado em Matemática pela Universidade Estadual de Londrina. Professor da rede pública Estadual do Paraná, Brasil. Email: jeankkuboyama@ hotmail.com.
} 
Cycle and obtaining the academic performance foreseen by the pedagogical proposal, the indigenous student can enroll in the desired undergraduate course. In this article we report the importance of Mathematics, one of the areas of knowledge addressed by an educator, and its possibilities to explore the potentialities and abilities that work with Problem Solving and Mathematical Investigations can develop in professionals of all areas of knowledge. The report of part of a lesson episode reveals that Mathematics can provoke reflection and give active participation of the student, making decisions, making choices, testing the validity of their choices.

Keywords: "Mathematics education", "Indigenous students", "Intercultural cycle", "Indigenous higher education".

\section{Introdução}

O presente artigo intenciona refletir sobre o ensino da Matemática a partir da experiência do Ciclo Intercultural de Iniciação Acadêmica de Estudantes Indígenas, experiência desenvolvida na Universidade Estadual de Londrina ${ }^{4}$ - Paraná/Brasil, como uma possibilidade de interculturalidade entre conhecimentos tradicionais com conhecimentos acadêmicos, no recente e desafiador contexto de ingresso e permanência de jovens indígenas na Educação Superior pública brasileira. Os autores desse trabalho estão vinculados a essa experiência na universidade estudada, sendo um educador-bolsista e dois professores orientadores e pesquisadores desta temática.

Emergentes no Brasil a partir do ano de 2002, as primeiras experiências de ingresso de indígenas em universidades públicas brasileiras se efetivaram ineditamente no estado do Paraná, sendo a Universidade Estadual de Londrina - UEL, uma das primeiras universidades públicas do país a receber membros de sociedades indígenas como seus estudantes. O ineditismo da experiência paranaense se constituiu em uma política pública de Educação Superior Indígena orientada pela Lei Estadual n. 13.134/2001, alterada pela Lei Estadual n.14.995/2006, prevendo aos indígenas, habitantes no território paranaense, o direito a vagas suplementares e uma política de ingresso específico nas Instituições Estaduais de Ensino Superior.

Para garantir o ingresso de candidatos indígenas, desde 2002, são organizados os Vestibulares dos Povos Indígenas do Paraná. No período de 2002 a 2017, foram realizadas 17 edições desse vestibular de forma itinerante nas IES públicas do Paraná, possibilitando o ingresso de indígenas nas IES Estaduais e garantindo progressivamente contornos mais específicos para essa política pública de Educação Superior Indígena. Neste período, foram ofertadas 534 vagas distribuídas para todas as IES Estaduais do Paraná, ocupadas por acadêmicos indígenas em diversos cursos de graduação.

Um elemento inovador nesse processo foi a constituição da Comissão Universidade para os Índios (CUIA) no ano de 2006, responsável pela coordenação interinstitucional das ações de ingresso e permanência dos estudantes indígenas nas IES estaduais do Paraná e na Universidade Federal do Paraná. Desta forma, cada Universidade Estadual constituiu a sua

\footnotetext{
${ }^{4}$ Sigla: UEL
} 
CUIA local, criando um espaço institucional para acolhimento e acompanhamento dos estudantes indígenas, e indicando três representantes desta Comissão para compor a CUIA Estadual (AMARAL; SILVÉRIO, 2016).

Todavia, nos 16 anos de experiência de ingresso e permanência de jovens indígenas nas IES paranaenses, muitos limites e desafios se apresentam, dentre eles: as dificuldades financeiras para manterem-se nas cidades, as distâncias geográficas, os deslocamentos diários entre as aldeias e Universidade, a convivência no espaço urbano, a característica bilíngue de parte dos estudantes, a ausência de acompanhamento institucional das IES, dentre outros. Outrossim, um dos mais desafiadores se refere à fragilidade da escolarização básica dos estudantes indígenas. Esse aspecto se evidencia pelas dificuldades desses sujeitos em acompanhar as atividades acadêmicas, vindo a amplificar as manifestações de preconceito pelos colegas e professores não indígenas, o auto-preconceito e os índices de retenção nas series iniciais e de evasão (Capelo; Amaral, 2004; Paulino, 2008; Amaral, 2010; Angnes, 2010; Amaral, 2016).

Neste contexto, ao diagnosticar e analisar essa situação, a CUIA local da UEL criou o Ciclo Intercultural de Iniciação Acadêmica de Estudantes Indígenas (denominado comumente como "Ciclo Intercultural") como uma estratégia de afirmação e fortalecimento da presença indígena na universidade.

\section{A proposta do Ciclo Intercultural}

O Ciclo Intercultural de Iniciação Acadêmica de Estudantes Indígenas se constitui de uma ação institucional voltada para o fortalecimento da presença e atuação desses acadêmicos por meio da oferta de uma modalidade especial de graduação desenvolvida no período de um ano.

Essa experiência se constitui como resposta institucional e política diante da realidade de significativos índices de retenção e evasão de estudantes indígenas na UEL e nas demais Universidades Estaduais paranaenses. Vale destacar que, no período de 2002 a 2014, por meio do Vestibular dos Povos Indígenas do Paraná, foram ofertadas 66 vagas para ingresso de estudantes indígenas na UEL, sendo todas por eles ocupadas (Amaral; Rodrigues; Bilar, 2014). Além dos que tiveram direito à matrícula por meio de aprovação no vestibular, seis outros estudantes indígenas ingressaram na referida Universidade por meio de transferência externa, vindos de outras universidades estaduais. Desse modo, do universo de 72 estudantes indígenas que ingressaram na UEL até o ano de 2014, 32 deles desistiram dos seus cursos e da universidade, totalizando o percentual significativo de $44 \%$ de evasão ${ }^{5}$.

Outrossim, nesse contexto, até o mês de fevereiro de 2015, nove estudantes indígenas concluíram seus cursos, representando $25 \%$ do universo de acadêmicos indígenas que

\footnotetext{
${ }^{5}$ Dados sistematizados por equipe vinculada a projetos de pesquisa na Universidade estudada, no período de 2011 até 2017.
} 
ingressaram no período de 2002 a $2009^{6}$. Apesar da compreensão (ainda que não acordada pela CUIA Estadual) sobre o direito que possuem os estudantes indígenas de concluírem sua graduação no tempo que for necessário (mesmo com os diferentes regimentos acadêmicos nas $\mathrm{IES}^{7}$ ), esse percentual de concluintes instiga a reflexão sobre as diversas causas em relação ao tempo definido como máximo pelas instituições para sua formação, assim como sobre as expectativas que possuem as comunidades indígenas para com a contratação e atuação dos profissionais formados nas terras indígenas e/ou no seu entorno (Amaral, et al., 2016).

Treze anos após os primeiros estudantes indígenas iniciarem seu percurso nos domínios da UEL, todo esse processo de aprendizagem desenhava-se como um caminho penoso e desafiador tanto para os estudantes quanto para os membros das CUIAs das IES. Ao longo desse período, a CUIA local da UEL passou por várias e diferentes composições e, desde o ano de 2012, tem sido constituída por docentes representantes de todos os cursos que possuem estudantes indígenas matriculados na instituição, por uma técnica do órgão responsável pelas ações de assistência estudantil, por uma diretora e um técnico da PróReitoria de Graduação (PROGRAD) e, atualmente, por seis representantes dos estudantes indígenas.

As ações da referida CUIA local passaram a intensificar as estratégias que visassem à permanência dos estudantes indígenas, garantindo um diálogo mais permanente com os caciques e lideranças das comunidades indígenas, com os estudantes indígenas e com os respectivos cursos envolvidos.

No mês de março de 2012, a CUIA local realizou sua primeira oficina de planejamento estratégico envolvendo docentes e estudantes indígenas, com o objetivo de fazer um balanço das ações institucionais desenvolvidas até aquele momento, além de identificar e debater os desafios que se apresentavam ao ingresso e à permanência dos estudantes indígenas na Educação Superior. Nessa oficina, foi identificado que um dos aspectos que limitavam a permanência desses sujeitos na universidade era a fragilidade dos conhecimentos que trazem da Educação Básica, dificultando o acompanhamento e o aprofundamento de conteúdos nas mais diferentes áreas, corroborando com o que apontam as produções acadêmicas já elaboradas até esse período sobre essa questão (Capelo, et al., 2004; Paulino, 2008; Amaral, 2010; Amaral, 2016). Mesmo que esse limite já se apresentasse para muitos estudantes não indígenas na UEL, para os estudantes indígenas ele se somava a outros aspectos desafiadores, tais como os preconceitos, a utilização da língua portuguesa como segunda língua para alguns acadêmicos, a distância geográfica da universidade à aldeia, a adaptação ao ambiente urbano, dentre outros.

\footnotetext{
${ }^{6}$ O período de 2002 a 2009 se justifica considerando a média de cinco anos para conclusão da graduação, o que inviabiliza que os ingressantes após 2010 sejam contabilizados para fins de conclusão.

7 Importante destacar que algumas Universidades Estaduais do Paraná regulamentam processos de integralização diferenciada para os estudantes indígenas, garantindo a eles o direito a um período mais prolongado para conclusão de seus cursos haja vista as especificidades socioculturais das quais eles pertencem. 
Como um dos encaminhamentos dessa oficina e por meio de um trabalho interdisciplinar realizado, a referida CUIA local iniciou a discussão e elaboração, em 2012, de um programa acadêmico complementar que servisse como uma ação afirmativa interna para amenizar as dificuldades encontradas pelos estudantes indígenas em permanecer e concluir a sua graduação de modo a estabelecer os processos interculturais fundamentais para sua formação. Chegou-se, desta forma, ao desenho da proposição de um ciclo, que antecedesse o início da matrícula do estudante nas disciplinas específicas de cada um dos cursos regulares de graduação da universidade.

A proposta de um ciclo introdutório foi apresentada e debatida junto aos estudantes indígenas então matriculados na instituição, bem como com todos os caciques e lideranças das terras indígenas localizadas na região norte do Paraná, em reuniões e oficinas com a finalidade de tornar legítimo o projeto. Após esse processo é apresentada pela CUIA local à Pró-Reitoria de Graduação, sendo debatida e tramitada pelas instâncias colegiadas superiores dessa instituição. A proposta foi aprovada e instituída por meio de resolução interna que criou o Ciclo Intercultural de Iniciação Acadêmica dos Estudantes Indígenas da UEL, estabelecendo sua implantação a partir do ano letivo de 2014. O Ciclo Intercultural já constou do edital de divulgação do XIII Vestibular dos Povos Indígenas do Paraná, realizado no final do ano de 2013, assegurando sua divulgação aos candidatos indígenas, de modo a garantir a ciência dos interessados em ingressar na instituição (Alves, 2016).

A proposta estabelece o Ciclo como um curso letivo coordenado pela CUIA local com o apoio da PROGRAD, estabelecendo os seguintes objetivos gerais:

- $\quad$ Promover formação acadêmica ampla e intercultural dos estudantes indígenas ingressantes na graduação, por meio de práticas educativas interdisciplinares e contribuir para a afirmação, respeito e visibilidade da presença indígena no ambiente acadêmico.

- $\quad$ Exercer cotidianamente o direito à diferença, de modo a auxiliar a construção de uma Universidade ciente do papel histórico que representa.

O estudante indígena ingressante a partir de 2014 na UEL, passa a ser matriculado no Ciclo Intercultural, obtendo todos os direitos e benefícios de qualquer acadêmico dessa universidade. Após cursar o Ciclo Intercultural e obter o desempenho acadêmico previsto pela proposta pedagógica, o estudante indígena poderá se matricular no curso de graduação desejado. A própria opção pelo curso desejado, passa a compor os conhecimentos debatidos ao longo do Ciclo, buscando amadurecer suas ideias e pretensões.

Considera-se que esse aspecto seja fundamental, pois tem-se constatado uma fragilidade na escolha de cursos de graduação pelos candidatos indígenas ao efetuarem sua inscrição nos vestibulares dos povos indígenas do Paraná, vindo a provocar um significativo índice de desistência e transferência de cursos, assim como recorrentes tentativas nas edições desse processo seletivo (Capelo, et al., 2004; Paulino, 2008; Rodrigues; Wawzyniak, 2009; Amaral, 2010; Angnes, 2010; Goulart, 2014; Amaral, 2016). O Ciclo Intercultural foi planejado como um espaço de reflexão, divulgação e alargamento da compreensão sobre o que é a universidade, sua dinâmica de funcionamento, assim como dos diversos cursos de graduação existentes. Isto fornece subsídios às escolhas profissionais que os candidatos 
DOI: https://doi.org/ 10.20396/zet.v26il.8650891

indígenas - com influência e apoio ou não de sua família e de sua comunidade de pertença deverão indicar.

Segundo Guerra; Amaral; Ota (2016), a proposta pedagógica do Ciclo Intercultural se estrutura a partir de um módulo anual denominado de Estudos Interculturais de Iniciação Acadêmica, com uma carga horária de 480 horas letivas. Esse módulo apresenta-se organizado por quatro eixos temáticos, que orientam bimestralmente e de forma interdisciplinar os conteúdos selecionados e as atividades planejadas pela equipe de coordenação do curso e pelos educadores. Os eixos temáticos foram escolhidos a partir das discussões realizadas junto aos estudantes indígenas, às lideranças indígenas e a equipe da CUIA local, relacionando-se com questões históricas e políticas vivenciadas pelos povos indígenas no Brasil (Alves, 2016).

Em sua pesquisa de mestrado, Alves (2016) descreve a organização do Ciclo Intercultural a partir dos seus eixos curriculares e atividades. $\mathrm{O}$ primeiro eixo temático, denominado Terra e Identidade, trata da questão dos pertencimentos, das identidades e dos valores culturais dos estudantes indígenas na relação direta e orgânica com seu grupo étnico e suas comunidades de pertença. Toma a expressão oral como elemento gerador para que esses novos sujeitos - agora acadêmicos e indígenas simultaneamente - se apresentem e se manifestem por meio de suas histórias de vida, de suas narrativas acerca das inquietações, dúvidas e descobertas desse velho-novo universo acadêmico. Pauta nesse momento formativo o debate acerca das territorialidades das quais pertencem esses estudantes compreendendo "a terra como espaço de memória e de fronteira étnica. A terra como corpo físico: os novos olhares - senso comum, religião, ciência e o olhar estético" (UEL, 2013). Busca refletir ainda as territorialidades e as relações sociais que passarão a construir e a conviver no espaço da Univer-cidade (Amaral, 2010).

O segundo eixo temático, Ciência e Saúde, ao discutir a questão do processo saúdedoença nos diferentes contextos socioculturais e dos modos de vida e dos hábitos ligados à saúde e à prevenção de doenças, insere a reflexão sobre a construção do olhar da ciência com finalidade de intervenção na vida cotidiana. Situa, para os estudantes indígenas - todos eles pertencentes a grupos étnicos de tradição oral - o sentido e o papel da escrita, do texto dissertativo, da metodologia científica de trabalho e das formas de apresentação do discurso científico.

O terceiro eixo temático, Cidadania e Sustentabilidade: cidadania e políticas públicas, debate os valores, a conduta ética e étno-ética (Cardoso De Oliveira, 2006) e a cidadania no universo pluralista das sociedades contemporâneas. Propõe-se uma reflexão sobre os modos de vida, os meios de comunicação de massa e a comunicação comunitária, o desenvolvimento tecnológico, a inclusão digital, a sustentabilidade e a volatilidade do conhecimento; instiga a reflexão em torno dos modos e alternativas de produção sustentável nas comunidades indígenas, a partir da iniciação à investigação inserindo a perspectiva qualitativa e a perspectiva quantitativa, por meio de estratégias de leitura e intertextualidade. 
Finalmente, o eixo Cotidiano Acadêmico cuja discussão central é voltada para o exercício científico cotidiano e para a compreensão da realidade que o exercício profissional da carreira escolhida exige. A vida acadêmica é apresentada como exercício do diálogo entre o dia a dia da universidade e os modos de vida nas terras indígenas, na perspectiva da formação permanente do futuro profissional indígena em seu duplo pertencimento (Amaral, 2010).

Guerra; Amaral; Ota (2016) evidenciam que os eixos temáticos inspiram e orientam a organização formal de dois blocos de atividades do Ciclo Intercultural, sendo um de natureza teórica e outro de natureza prática, ainda que ambos tenham articulações teórico-práticas intimamente associadas.

O primeiro bloco se organiza a partir de áreas de conhecimento - das ciências da natureza, da matemática e da língua portuguesa, sendo desenvolvidas por meio de aulas semanais, de forma concentrada, no período noturno, de segunda à quarta-feira. As aulas são ministradas por educadores-bolsistas orientados por docentes especialistas das respectivas áreas, vinculados ao Programa de Formação Intercultural ${ }^{8}$ dessa instituição. Os conteúdos e metodologias desenvolvidos em cada uma dessas áreas são balizados pelo intercruzamento de dois aspectos fundamentais: o olhar macro conceitual que contextualiza, problematiza e propõe uma reflexão crítica mais ampla; e o olhar micro compreendendo as estruturas e os conceitos essenciais que definem a relação entre método e objeto nos três campos distintos. A composição dessa base curricular toma como princípio o permanente diálogo entre as realidades vivenciadas pelos estudantes indígenas nas terras indígenas e pelos povos indígenas no Paraná e no Brasil e o campo das ciências contemporâneas.

O segundo bloco se organiza por meio de atividades de diversos formatos tais como: rodas de conversa com a participação de convidados especialistas em um tema específico vinculado à temática do módulo; visitas para conhecer diferentes órgãos e espaços existentes na Universidade tais como: as bibliotecas central e setoriais, laboratórios (de ciências, de anatomia, de astronomia, de tecnologia, etc.), museus, hospitais-escola, dentre outros; visitas a experiências de cooperativas comunitárias e outras organizações populares na região; encontros com coordenações de colegiados de cursos desejados pelos estudantes indígenas do Ciclo, bem como com representantes estudantis de centros acadêmicos; e oficinas de síntese das atividades realizadas nos eixos temáticos bimestrais. As atividades desse bloco se realizam semanalmente as quintas e sextas-feiras, no período noturno e, eventualmente, durante o dia.

Como parte dessas atividades, pelo menos uma vez por bimestre, são organizadas atividades de campo nas terras indígenas, de acordo com as temáticas definidas nos módulos

\footnotetext{
8 Programa de ensino de caráter permanente criado no ano de 2003 para o desenvolvimento de ações pedagógicas de acompanhamento dos estudantes indígenas na UEL, vinculando professores, estudantes indígenas e não indígenas. Foi a primeira iniciativa institucional criada por professores e gestores dessa Universidade logo após o ingresso dos primeiros estudantes indígenas. Com a criação da CUIA local em 2006, as ações desse Programa passam a ser associadas aos encaminhamentos dessa Comissão (Amaral, 2010). Os educadores-bolsistas e professores orientadores estão vinculados academicamente a esse programa.
}

Zetetiké, Campinas, SP, v.26, n.1, jan./abr. 2018, p.240-257

ISSN 2176-1744 
e as peculiaridades de organização das aldeias, contando com a participação de todos os estudantes indígenas, dos estudantes-bolsistas e de docentes da CUIA local. Trata-se de um estudo do meio para, na concretude do campo de trabalho, refletir sobre os conceitos tratados no módulo, agora tendo a realidade da aldeia como objeto científico. Nessas atividades são realizados contatos com profissionais indígenas e não indígenas que atuam nas aldeias, lideranças indígenas e sábios das comunidades. Nesse contexto, é fundamental que o discente indígena vivencie esse duplo pertencimento: como indígena - Guarani ou Kaingang - e como estudante universitário, que passa a ter como objeto de estudo o próprio território, do qual pertence e em que vive, sendo dele sujeito (Amaral, 2010).

As avaliações de desempenho acadêmico dos estudantes do Ciclo ocorrem de forma processual e diagnóstica, contando com a participação e reflexão permanente de todos os sujeitos envolvidos. Os estudantes devem atingir, no mínimo, setenta e cinco por cento de frequência sendo que as avaliações se realizam por meio de diversos instrumentos que são elaborados conforme os objetivos específicos de cada eixo temático. Ao final de cada eixo bimestral, os resultados das avaliações realizadas são discutidos por meio de roda de conversa com todos os envolvidos, assim como de forma individual, definindo-se estratégias pedagógicas de recuperação, respeitando as dinâmicas particulares de cada acadêmico. Nesse momento, é também avaliada a frequência dos estudantes, identificando-as e refletindo sobre as ausências das atividades, bem como possíveis desmotivações no processo (Alves, 2016; Guerra, et al., 2016).

No final do ano letivo, aqueles que cursarem presencialmente e sequencialmente o Ciclo e alcançarem aproveitamento satisfatório poderão escolher e matricular-se no curso de graduação desejado. O Ciclo Intercultural intenciona prepará-lo para essa escolha, por meio de pesquisas e discussões sobre as profissões por eles indicadas, assim como por meio de diálogos com docentes, profissionais e estudantes dessas respectivas áreas. O estudante que não reprovar, simultaneamente, por nota e insuficiência de frequência poderá participar por mais uma vez do Ciclo.

Em síntese, essa experiência - única e inédita no cenário nacional vinculada à temática da Educação Superior Indígena - aborda vários temas controversos e de difícil condução no ambiente universitário. Vem evidenciando que a permanência dos estudantes indígenas no cotidiano acadêmico é um exercício diário, tanto desses sujeitos quanto de professores e da própria instituição na busca de uma educação superior pública e intercultural que abrigue uma efetiva troca de saberes. Desta forma, a universidade passa a ser reconhecida como um espaço de fronteira étnica e social (Barth, 1998) que passa a ser progressivamente ocupada pelos jovens indígenas em constantes experiências de conflitos, consensos, alianças e resistências. A apropriação dos conhecimentos acadêmicos - dentre eles a Matemática passa a ser uma estratégia e uma ferramenta para conhecer melhor o universo não indígena.

\section{A Importância da Matemática no Ciclo Intercultural}

Pretendemos, nessa parte do texto, justificar a inserção da Matemática na experiência 
do Ciclo Intercultural e explorar as potencialidades e habilidades que o trabalho com Resolução de Problemas e as Investigações Matemáticas podem desenvolver nos profissionais de todas as áreas do conhecimento.

Por muito tempo a Matemática foi apresentada nas escolas como um conjunto de técnicas e procedimentos passo a passo, em uma abordagem conhecida como mecanicista (Van Den Heuvel-Panhuizen, 2010). Surgiram muitos movimentos na tentativa de mudar a perspectiva do ensino da Matemática, dentre elas a Matemática Moderna (Pedrochi Junior, 2012; SANTOS, 2014), a Educação Matemática Realística (Pires, 2013).

A Educação Matemática Realística, considera a Matemática como uma atividade humana. Seu precursor, Hans Freudenthal, alemão que desenvolveu seus trabalhos na Holanda, posicionou-se em desfavor da Matemática Moderna. "Duas das ideias centrais da abordagem RME são a reinvenção guiada e a matematização. Para Freudenthal, na escola deveria ser dada a oportunidade de o aluno reinventar a Matemática sob a orientação do professor" (Pires, 2013, p. 24).

De acordo com Kilpatrick (2008-2014, p.38, tradução nossa),

Como Klein e Pólya, Hans Freudenthal voltou-se para a educação matemática no início da vida. Como ele disse: "Toda a minha vida fui um pobre professor e, para tirar o melhor proveito, comecei a pensar sobre a educação muito novo" (citado em Goffree, 1993, página 22). [...] um dos cursos que Freudenthal deu foi intitulado Matemática primária de um ponto de vista avançado (Van Est, 1993, p.161). No início da Segunda Guerra Mundial, ao dar aulas em aritmética a seus dois filhos, ele começou a estudar didática da aritmética e faz anotações para um livro de "didática da aritmética" que, infelizmente, existe apenas em forma manuscrita fragmentada (Goffree, p 24). Antes e durante a guerra, Freudenthal participou do Dutch Mathematics Study Group, que discutiu questões em educação matemática, tentou desenvolver currículos o que proporcionou a Freudenthal o que ele chamou de "faculdade de educação matemática" (citada em Goffree, p. 26).

Na história da Educação Matemática Klein, Polya e Freudenthal foram os precursores de preocupações que ultrapassam o conteúdo. Surgem as primeiras sugestões e reflexões a respeito da importância da Resolução de Problemas como estratégia de aula. (Kilpatrick, 2008-2014).

Na proposta do projeto Intercultural, a Matemática é desenvolvida na perspectiva da Resolução de Problemas e das Investigações Matemáticas. De acordo com essas estratégias os estudantes indígenas passam por experiências consideradas essenciais para a formação de um sujeito social, crítico e atuante na sociedade em que vive. A condução da Matemática por meio de Resolução de Problemas insere os estudantes em:

- interpretação de tarefas;

- elaboração de estratégias para resolver problemas;

- execução das estratégias escolhidas e

- reflexões a respeito da resposta encontrada. 
DOI: https://doi.org/ 10.20396/zet.v26il.8650891

Uma aula na perspectiva da Investigação Matemática oferece ao aluno a oportunidade de descobrir algo, resumidamente, oportuniza que o estudante

- interprete uma situação;

- defina um problema que julgue interessante responder e que esteja inserido na situação apresentada;

- escolha estratégias que possam resolver o problema definido;

- realize os procedimentos para execução da estratégia escolhida e

- reflita a respeito da resposta.

Acreditamos que dar aos alunos a possibilidade de passar por essas etapas durante a aula e se envolver com os conteúdos matemáticos, seja um caminho que mostre uma perspectiva de Matemática próxima das ideias de Freudenthal, como uma atividade humana, contando com a participação ativa do estudante, tomando decisões, fazendo escolhas, testando a validade das suas escolhas. Essas ações corroboram para o fortalecimento dos jovens indígenas no espaço acadêmico.

As estratégias de Resolução de Problemas e Investigações Matemática consideram como ponto de partida a escolha de uma boa tarefa, podendo ou não privilegiar um conteúdo específico. Essa possibilidade, valorizada pela Educação Matemática Realística, vai ao encontro dos ideais do Ciclo Intercultural que, ao receber os indígenas, foca em prepará-los para a vida acadêmica em um curso superior.

Consideramos, ao escolher as tarefas desenvolvidas durante os primeiros anos do Ciclo, a possibilidade de serem resolvidas por diferentes estratégias e abordarem mais de um conteúdo. A escolha das tarefas também considerou os eixos temáticos bimestrais. Após quatro anos de desenvolvimento do Ciclo, a coletânea de tarefas que foram trabalhadas com os estudantes revela que os conteúdos mais abordados foram: Sistema de Numeração Decimais, Operações Fundamentais, Linguagem Algébrica não-formal e formal, Equações, Funções, Estudo de Padrões e Regularidades, Proporcionalidade, Matemática Financeira, Geometria; conteúdos necessários para alunos de qualquer que seja a área, ofertados pela UEL. Na sequência exemplificamos a relação da Matemática com alguns cursos.

- Profissionais das áreas de História, Filosofia, Sociologia e áreas afins, precisam evitar o anacronismo e, para isso devem ter uma boa noção de tempo e espaço.

- Profissionais das áreas Médicas, Enfermagem, trabalham com ideias fundamentais da proporcionalidade e, consequentemente com resolução de equações.

- Profissionais das áreas de Direito, Administração, Economia, precisam ter alto poder de generalização e para fazê-lo necessitam observar regularidades e definir padrões. O estudo de Geometria e Funções, por exemplo, contribui 
muito para o desenvolvimento dessas habilidades.

Além da importância das estratégias e dos conteúdos anunciados, a orientação é para que o educador que trabalha com a Matemática considere a Etnomatemática.

Para entender o que é Etnomatemática podemos começar pela formação da palavra. $\mathrm{O}$ prefixo Etno se refere à Etnia, que remete a um grupo de pessoas de mesma cultura, língua própria, podemos dizer ainda que com características culturais bem delimitadas. O Brasil é composto por uma quantidade muito grande de grupos étnicos. De acordo com os dados do Instituto Brasileiro de Geografia e Estatísticas, no censo de 2010, foram identificadas 305 etnias e reconhecidas 274 línguas.

Para o Educador Matemático Ubiratan D’Ambrosio (1998, p. 81),

Etnomatemática: o prefixo etno é hoje aceito como algo muito amplo, referente ao contexto cultural e, portanto, inclui considerações como linguagem, jargão, códigos de comportamento, mitos e símbolos; matema é uma raiz de difícil entendimento que vai na direção de explicar, de conhecer, de entender; tica sem dúvida, vem de techne, que é a mesma raiz de arte e de técnica. Assim, etnomatemática é a arte ou técnica de explicar, de conhecer, de entender, nos diversos contextos culturais.

Para Fonseca (2015, p. 160),

[...] o grande enigma da Etnomatemática atualmente é: como se apropriar do conhecimento étnico na sala de aula, buscando uma educação com significado? Como fazer a ponte entre este conhecimento e o conhecimento dito institucional? Para o autor, o sentido de espiral da modelagem matemática visa em modelar matematicamente conceitos, idéias, mitos, jogos, artefatos, etc., começando pelo saber-fazer do grupo (Etnomatemática), seguindo depois por modelar a realidade do grupo.

O que embasa as ações desenvolvidas nas aulas de Matemática do Ciclo são as teorias expostas anteriormente. É importante ressaltar ainda que os estudantes indígenas participantes do Ciclo e durante o tempo de formação no curso superior, recebem uma bolsa mensal de assistência para que eles possam efetivar seus estudos ${ }^{9}$. Esse pode ser um fato que causou interesse dos alunos pelo assunto abordado no relato que segue.

O relato que apresentamos na secção seguinte foi planejado levando em conta a abordagem da Educação Matemática Realística, as Estratégias de Resolução de Problemas e Investigação Matemática e a Etnomatemática.

\section{Relato do desenvolvimento de uma atividade no Ciclo Intercultural}

A Etnomatemática é considerada no planejamento das aulas de Matemática com o intuito de ajudar os alunos a utilizarem as situações do seu cotidiano no processo de ensino e

\footnotetext{
${ }^{9}$ Atualmente, a bolsa é de R \$ 900,00 e de R \$ 1350,00 para os que comprovam maternidade ou paternidade. 
DOI: https://doi.org/ 10.20396/zet.v26il.8650891

de aprendizagem dessa disciplina em sala de aula. As tarefas organizadas baseiam-se na apresentação de situações abertas e sugestivas que exigem dos alunos participação e envolvimento para buscar suas próprias respostas.

Um dos autores desse artigo foi o educador-bolsista que trabalhou com a tarefa aqui relatada, turma do Ciclo Intercultural do ano de 2016. Apresentamos o relato em primeira pessoa.

\section{Tarefa: Planejamento Financeiro}

Acredito que uma aula de Matemática não se resume a cálculos de operações, sendo assim, para elaboração de uma aula, sempre levava em conta assuntos que os próprios alunos poderiam ter vivenciado no seu dia, favorecendo o envolvimento dos alunos com a aula. Em muitos momentos procurei instigar, transformar a aula em um debate e assim conseguia prender a atenção do estudante e envolvê-lo na aula.

Entre os temas discutidos em uma roda de conversa, um que mais me chamou atenção foi o cotidiano financeiro dos estudantes, percebi que alguns deles estavam em situação de endividamento, não conseguiam pagar suas contas em dia e que o atraso dos pagamentos se dava por conta do descontrole financeiro, uma vez que, para muitos deles, era muito novo e recente conviver na cidade e na universidade. Aproveitei a conversa para definir o tema que iríamos estudar, assim envolveria o contexto escolar com as necessidades e mudanças que a sociedade vem enfrentando por meio de fenômenos e situações existentes no contexto social, econômico e político.

Foi elaborada uma tarefa: "Planejamento Financeiro", sendo dividida em dois momentos: no primeiro, trabalhamos com um estudo de caso, com objetivo de planejar as despesas e receitas, e em um segundo momento, trabalhamos no laboratório de informática, em construções de planilhas, gráficos e tabelas financeiras para a organização de gastos, concluindo a atividade com a elaboração de um orçamento familiar.

O estudo de caso se tratava de uma família que não tinha um planejamento financeiro no seu cotidiano. Em uma das situações, a família optava por pagar o valor mínimo da fatura do cartão de crédito. Essa situação teve grande repercussão entre os alunos, pois muitos se identificaram com o caso. Alguns estudantes relataram que tiveram fácil acesso ao cartão de crédito, acabaram utilizando-o de forma desenfreada e não conseguiam pagar a fatura integralmente.

Quando aconteciam relatos desse tipo, eu procurava estabelecer diálogos a respeito de assuntos que abordam conteúdos matemáticos e levá-los a reflexão. Aproveitei o contexto e trabalhamos com taxas de juros.

Professor: Se eu deixar de pagar 400 reais da fatura do meu cartão de crédito, o que acontece no mês seguinte?

Estudante 1: No mês que vem esse valor não será mais 400 reais, vai "crescer".

Estudante 2: E se você gastar mais, vai aumentar o valor mais ainda. 
DOI: https://doi.org/ 10.20396/zet.v26il.8650891

Professor: Vamos supor que eu não gaste mais porque queira quitar minha dívida, em torno de quanto ficará o valor da fatura para poder ser quitada?

Estudante 3: Precisa saber quanto está a taxa de juros.

Professor: Hoje, a taxa de juros do cartão de crédito está em torno de $11 \%$.

Alguns alunos realizaram alguns cálculos, outros pareciam ficar meio sem saber como fazê-los.

Estudante 2: Bom, eu fiz aqui e deu 44 reais.

Estudante 4: Acho que está errado, porque ele já devia 400, como deu só 44? Não vai aumentar o valor?

Estudante 2: 44 reais é só o que vai subir.

Professor: E como você chegou em 44 reais?

Estudante 2: Eu fiz aqui na calculadora, 400 vezes 11 .

Silêncio. Deixei os alunos pensando.

Professor: E então? O que vocês acham?

Estudante 4: Eu conferi aqui e, 400 vezes 11 dá 4400 e não 44.

Estudante 2: Eu cortei os dois zeros, porque sempre que é porcentagem a professora mandava cortar dois zeros.

Professor: Então quanto ficaria a fatura no mês seguinte?

Estudante 2: 400 mais 44, que dá 444 reais.

Estudante 3: Até que não é muito, um aumento de 44 reais.

Professor: E se fosse 800 reais?

Depois de algum tempo.

Estudante 2: $O$ dobro, será 888 reais.

Estudante 1: É, subir 88 reais já não é tão pouco!

$[\ldots]$

Com essa introdução, foi possível discutir com os estudantes qual o significado matemático de "cortar os dois zeros", quais as várias formas de calcularmos porcentagem, utilizando calculadora ou não, construímos tabelas utilizando proporcionalidade, dentre outros.

Com os exemplos discutidos com os estudantes, foi possível abordar a questão do uso consciente do cartão de crédito para evitar problemas futuros. Os alunos pareciam interessados na discussão, os seus relatos e expressões mostravam a crença de que saber Matemática pode ser um dos caminhos para resolver problemas reais. Resolvi dividir a sala em dois grupos, para compararmos os pontos fracos e fortes do uso de cartão de crédito, que resultou em uma discussão acirrada, e para cumprir o meu papel de educador, procurei ser o mediador encaixando os conteúdos nos fatos e situações levantadas durante as conversas:

Tabela 1: situações levantadas nas conversas.

\section{Argumentos a favor do Cartão de Crédito}

\section{Argumentos contra o Cartão de Crédito}


Quando a gente precisa comprar algo e não tem dinheiro, podemos comprar.

As pessoas que tem cartão de crédito são bem vistas e bem atendidas nas lojas.

Não precisamos andar com dinheiro.

É possível parcelar a conta.

Substitui o cheque pré-datado.
Pode-se gastar mais do que ganhamos e aí o dinheiro não dá para pagar.

Quando recebemos, pagamos o cartão e ficamos sem dinheiro.

Se não pagarmos o total da fatura teremos que pagar juros.

Os juros do cartão são altos.

Fonte: dos autores.

Por fim, os alunos chegaram a conclusão que usar os cartões de crédito sem planejamento pode trazer muitas dívidas, gerando inúmeras dificuldades para superá-las.

Uma das estudantes, muito tímida, quase no final da atividade disse: "ter cartão de crédito pode ser bom, se seu uso for consciente, pois pra conseguir um cartão de crédito é muito fácil, o dificil é controlar os gastos". Quando ouvi essa sua manifestação, ela que quase não falava em sala de aula, me senti muito realizado como seu educador.

Levando em conta que a informática é parte integrante da vida do estudante, para o segundo momento da aula, planejamos a utilização de uma ferramenta tecnológica; planejamos uma aula para os estudantes indígenas no laboratório de informática do Departamento de Matemática.

Apresentei alguns gráficos e tabelas com diferentes taxas cobradas pelos principais bancos da nossa região.

Analisando os dados ficou evidente que os alunos conseguiram comparar diferentes ofertas, visando à tomada de decisão informada e responsável, agir de forma eficaz em relação a assuntos financeiros relacionados com as suas necessidades. Observou-se também a indignação dos alunos, a partir do momento que iam fazendo as comparações entre os gráficos e tabelas. Alguns deles relataram que começaram a compreender o motivo que alguns bancos facilitam o acesso aos serviços bancários, cobrando taxas de juros mais altas que os outros.

Enquanto educador no Ciclo, percebi que conhecer as tecnologias e saber fazer uso delas, na aula de matemática, permite desenvolver autonomia e capacidade crítica nos alunos.

Refletindo a respeito das conversas que o assunto possibilitou e que, neste caso, somente o conhecimento matemático pode subsidiar, acreditamos que foi possível prever as consequências positivas e negativas de diferentes decisões e ações, no que diz respeito ao 
funcionamento das finanças, seleção de informações, tomadas de decisões com base nessas informações.

O desenvolvimento da capacidade de fazer escolhas fundamentadas e informadas compreende a análise e julgamento com base em informações e decisões efetivas. Isso é ainda mais evidente quando o assunto versa sobre o uso e gerenciamento do dinheiro.

Para concluir a aula e mobilizar os alunos, promovi uma nova discussão sobre o uso e gerenciamento do dinheiro, lançando as seguintes questões: "Você sabe o que é renda familiar?", "E qual a diferença entre salário bruto e salário líquido?", "Você considera importante que uma família planeje suas despesas?". Nesse momento senti alguma dificuldade dos alunos falarem, até pelo fato de que o assunto envolvia identificar a renda familiar como a somatória dos valores recebidos pelos membros da família, então tive que instigá-los a justificar suas falas, para que reconhecessem que uma das vantagens do planejamento das despesas é o controle tanto do orçamento, ou seja, não gastar mais do que se ganha, quanto das emoções, para não comprar tudo o que vê, necessidade do conhecimento das reais condições para melhor administrá-las. A partir daí, aproveitei da situação e expliquei algumas dúvidas dos alunos, como o que é salário líquido, por exemplo: salário do qual já foi descontadas as contribuições obrigatórias, como a do INSS (Instituto Nacional de Seguridade Social) e do IRPF (Imposto sobre a Renda da Pessoa Física). Essa atividade se realizou tendo em vista a compreensão de que muitos deles trabalham em funções como: professores de escolas estaduais indígenas ou em outras funções assalariadas dentro ou fora da terra indígena; várias famílias nas terras indígenas das quais eles pertencem recebem benefícios sociais pelas diferentes instâncias governamentais, o que agrega a renda familiar. Todos os estudantes indígenas matriculados nas Universidades Estaduais do Paraná recebem bolsa-auxílio mensal pelo Governo do Estado (Amaral, 2010; Alves, 2016).

Com os alunos ainda mobilizados, apresentei uma planilha com os controles de entradas e saídas e propus que construíssem uma planilha no Excel para administrar o seu orçamento familiar. Assim, enquanto os alunos começaram a desenvolver o que foi proposto, fui atendendo os alunos individualmente, para realizar intervenções. Observei os registros que estavam sendo realizados e verifiquei que apareceram diferentes estratégias de resolução, no momento da discussão final, fiz questão de compartilhar com todos as diferentes resoluções. Por exemplo, um aluno, além de montar a planilha construiu gráficos de acordo com as tarefas desenvolvidas em uma aula de tratamento de informação.

Para finalizar essa etapa os alunos expuseram para a turma as suas considerações em relação à justificativa escolhida no modelo de seu orçamento familiar. O mais importante foi promover um debate acerca das justificativas apresentadas tendo em mente que administrar um orçamento familiar é fazer escolhas confrontando custos e benefícios. Um fato que me chamou atenção foi que um aluno escolheu como mais vantajoso optar pelas compras a prazo, justificando que as prestações não seriam reajustadas, e que a prestação assumida não comprometeria consideravelmente o orçamento familiar, visto que outros imprevistos 
DOI: https://doi.org/ 10.20396/zet.v26il.8650891

poderiam ocorrer. Já outro aluno optou por efetuar suas compras à vista, ou até mesmo adiar sua aquisição justificando ser a opção mais vantajosa economicamente.

Em uma próxima tarefa, propus outros desafios, com situações problemas no qual os alunos tiveram que encontrar um caminho mais viável. No final da atividade, muitos alunos reconheceram que pagar à vista pode ser mais viável financeiramente.

\section{Conclusões}

O desafio de fortalecer a presença e as trajetórias dos estudantes indígenas nas Universidades Estaduais do Paraná, e mais especificamente na UEL, tem provocado iniciativas pessoais e institucionais no âmbito acadêmico e junto às comunidades indígenas. O processo de criação e desenvolvimento do Ciclo Intercultural, aqui relatado, demonstra a possibilidade de emergência de novas e criativas iniciativas institucionais que podem e devem ser legitimadas pelas sociedades indígenas envolvidas.

$\mathrm{O}$ fato dos estudantes indígenas estarem juntos em uma mesma sala e realizarem as mesmas atividades no primeiro ano de ingresso e de permanência na Universidade, corrobora para que eles possam, em grupo, encarar os primeiros desafios de estarem em uma Instituição de Ensino Superior pública. O desenvolvimento de uma proposta pedagógica voltada exclusivamente para os povos indígenas, provoca a reorganização dos saberes e metodologias no campo da Educação Superior, bem como contribui para o diálogo e a interculturalidade, necessários para o fortalecimento desses sujeitos. A Matemática, deste modo, se insere numa perspectiva interdisciplinar, articulada e orientada por eixos temáticos bimestrais intimamente associados às realidades vivenciadas pelos povos indígenas no Paraná. Os eixos temáticos inspiram a participação dos estudantes e educadores num diálogo marcado pelo sentido e significado de estar na universidade, mantendo os pertencimentos étnico-comunitários.

A perspectiva de Matemática escolhida para as atividades no Ciclo Intercultural, oportuniza o desenvolvimento de habilidades importantes na formação de diferentes profissionais e tem se mostrado facilitadora do envolvimento dos estudantes na aula, provocando reflexões, tomada de decisões, fazendo escolhas, testando a validade das suas escolhas, como apresentado no episódio de aula apresentado.

\section{Referências}

Alves, R. (2016). O Ciclo Intercultural de Iniciação Acadêmica para estudantes indígenas da Universidade Estadual de Londrina. Dissertação de Mestrado Profissional em Políticas Públicas. Maringá: Universidade Estadual de Maringá.

Amaral, W.R. (2010). As trajetórias dos estudantes indígenas nas universidades estaduais do Paraná: sujeitos e pertencimentos. Tese de Doutorado em Educação. Curitiba: Universidade Federal do Paraná.

. (2016). Indígenas nas universidades estaduais do Paraná: sujeitos, trajetórias e pertencimentos. In: Amaral, W.R., \& Fraga, L., \& Rodrigues, I. C.; (org). Universidade para indígenas: a experiência do Paraná. Rio de Janeiro: FLACSO, GEA; UERJ, LPP. 
Amaral, W. R., \& Rodrigues, M. A., \& Bilar, J. A. B. (2014). Os Circuitos de Trabalho Indígena: Possibilidades e desafios para acadêmicos e profissionais Kaingang na gestão das políticas públicas. Revista Mediações, v. 19, n.2, Londrina. (pp. 129-145). Retirado em $\quad 30 \quad$ de setembro, 2017, http//www.uel.br/revistas/uel/index.php/mediacoes/issue/view/1065.

Amaral; W. R., \& Fraga, L. (2016). Educação escolar indígena no Brasil e no Paraná: constituição e articulação com o ensino superior. In: Amaral, W.R., \& Fraga, L., \& Rodrigues, I. C. (org). Universidade para indígenas: a experiência do Paraná. Rio de Janeiro: FLACSO, GEA; UERJ, LPP.

Amaral; W. R.,\& Silvério, D. M. F. (2016). A Comissão Universidade para os Índios: desafios na política de educação superior indígena. In: Amaral, W.R., \& Fraga, L., \& Rodrigues, I. C.; (org). Universidade para indígenas: a experiência do Paraná. Rio de Janeiro: FLACSO, GEA; UERJ, LPP.

Guerra, M. J., \& Amaral, W. R., \& Ota, M. I. N. A experiência do Ciclo Intercultural de Iniciação Acadêmica dos Estudantes Indígenas na UEL. In: Amaral, W.R., \& Fraga, L., \& Rodrigues, I. C.; (org). Universidade para indígenas: a experiência do Paraná. Rio de Janeiro: FLACSO, GEA; UERJ, LPP.

Angnes. S. J. (2010). O ensino superior para os povos indígenas: ingresso, permanência, desistência, conclusão dos estudantes indígenas da Universidade Estadual do Centro Oeste (UNICENTRO) - Paraná. Tese (Doutorado em Educação) - Universidade Federal do Paraná, Curitiba.

Barth, F. (1998). Grupos étnicos e suas fronteiras. In: Poutignat, P., \& Streifffenart, J. Teorias da etnicidade. São Paulo(SP): UNESP.

Capelo, M. R. C., \& Amaral, W. R. (2004). Quando a diferença faz a diferença: a presença de índios na Universidade Estadual de Londrina. Educação e Linguagem, v.7, n. 10, (pp.168-190).

Cardoso de Oliveira, R. (2006). Caminhos da identidade: ensaios sobre etnicidade e multiculturalismo. São Paulo: Editora Unesp; Brasília: Paralelo 15.

D’Ambrosio, U. (1998). Etnomatemática - arte ou técnica de explicar e conhecer; São PauloSP; Editora Ática; $4^{\mathrm{a}}$. Ed.

Fonseca, M.G., \& Lopes, F.R.F. (2015). A Matemática inserida naturalmente no contexto sócio-laboral: um caso de Etnomatemática. Revemat: Revista Eletrônica de Educação Matemática. Florianópolis (SC), v.10, n. 1, (pp. 150-161).

Goulart, A. C. (2014). Experimentar, contestar e refazer-se: caminhos de sonhos e enfrentamentos percorridos por acadêmicos Kaingang e Guarani na Universidade Estadual de Londrina - PR. (Mestrado em Antropologia) - Universidade Federal do Paraná, Curitiba.

Kilpatrick, J. (2008/2014). A Higher Standpoint. Materials from ICME 11. Retirado de: $\mathrm{http} /$ /www.mathuion.org/icmi /publications /icme-proceedings /.Regular lectures.(pp. 26-43).

Paulino, M. M. (2008). Povos indígenas e ações afirmativas: o caso do Paraná. Dissertação de Mestrado em Educação. Rio de Janeiro: Universidade Federal do Rio de Janeiro. 
DOI: https://doi.org/ 10.20396/zet.v26i1.8650891

Pedrochi Junior, O. (2012). Avaliação como oportunidade de aprendizagem em Matemática. Dissertação em Ensino de Ciências e Educação Matemática. Londrina: Universidade Estadual de Londrina.

Pires, M. N. M. (2013). Oportunidade para aprender: uma prática da reinvenção guiada na prova em fases. Tese de Doutorado em Ensino de Ciências e educação matemática. Londrina: Universidade Estadual de Londrina.

Rodrigues, I. C., \& Wawzyniak, J. V. (2009). Inclusão e permanência de estudantes indígenas no ensino superior público no Paraná - reflexões. 2006. Retirado em 15 de março, 2009, de: http//www.acoesafirmativas.ufscar.br/relatoriocuia.

Santos, E. R. (2014). Análise da produção escrita em matemática: de estratégia de avaliação a estratégia de ensino. Tese de Doutorado em Ensino de Ciências e Educação Matemática. Londrina: Universidade Estadual de Londrina.

Van Den Heuvel-Panhuizen, M. V. D. (2010) Reform under attack - Forty Years of Working on Better Mathematics Education thrown on the Scrapheap? No Way! In L. Sparrow, B. Kissane \& C. Hurst (Eds.). Proceedings of the 33th annual conference of the Mathematics Education Research Group of Australasia. Fremantle: MERGA.

Recebido em: 31/10/2017

Aprovado para publicação em: 03/04/2018 